\title{
Transdisciplinarity as a discipline and a way of being: complementarities and creative tensions
}

Cyrille Rigolot ${ }^{1 \times}$

Transdisciplinarity is generally defined by the inclusion of non-academic stakeholders in the process of knowledge production. Transdisciplinarity is a promising notion, but its ability to efficiently address the world's most pressing issues still requires improvement. Several typologies of transdisciplinarity have been proposed, generally with a theoretical versus practical dichotomy (Mode 1/ Mode 2), and effort has focused on possible linkages between different types. However, in the last two decades, transdisciplinarity has significantly matured to the extent that the classical theoretical versus practical distinction appears clearly limited. In this paper, a reframing of the debate is proposed by considering transdisciplinarity as a new discipline and as a way of being. The conception of transdisciplinarity as a discipline can be related to the recent development of the broader discipline of "integration and implementation sciences" (i2S), to which "practical" Mode 2 transdisciplinarity is a major contributor. When transdisciplinarity is considered as a way of being, it is inseparable from personal life and extends far beyond the professional activities of a researcher. To illustrate this conception, the work and life of Edgar Morin can be used as an exemplary reference in conjunction with other streams of thought, such as integral theory. Transdisciplinarity as a discipline and transdisciplinarity as a way of being have complementarities in terms of researchers' personal dispositions and space for expression in academia. The proposed distinction also raises the question of the status of consciousness in transdisciplinary projects, which may be a fruitful controversial topic for the transdisciplinary research community. 


\section{Introduction}

$\mathrm{n}$ the context of unprecedented worldwide crises, transdisciplinarity is increasingly mentioned as a promising way of producing knowledge and decision-making (Lang et al., 2012). Transdisciplinarity is often characterized by the inclusion of non-academic stakeholders in the process of knowledge production (Scholz and Steiner, 2015). The notion of transdisciplinarity emerged in the 1970s and developed in different streams that correspond to different communities and contrasting research practices (Klein, 2014). Several typologies have been proposed to characterize these different streams and their relationships. In one of the most common typologies, based on the work of Gibbons et al. (1994) in the sociology of science, Scholz and Steiner (2015) distinguish two modes of transdisciplinarity: "Mode 1" transdisciplinarity, which is mostly theoretical, is motivated by a general search for a "unity of knowledge" and corresponds to an "inner-science activity", while "Mode 2" transdisciplinarity, which is mostly practical, is typically characterized by the inclusion of stakeholders in participatory problem-solving approaches that are applied to tangible, real-world problems (Scholz and Steiner, 2015). Mode 1 transdisciplinarity is typically associated with the quantum physicist Basarab Nicolescu's proposal of a methodology based on three axioms: (1) levels of reality, (2) the principle of the hidden third, and (3) complexity. These axioms are extensively developed in the literature (Nicolescu, 2010; McGregor, 2015a). In another famous typology, Max-Neef (2005) proposes distinguishing "weak transdisciplinarity", which can be applied "following traditional methods and logic", and "strong transdisciplinarity", notably inspired by Nicolescu's work, which is characterized by a specific quantum-like logic and breaks with the assumption of a single reality (Max-Neef, 2005). From this perspective, transdisciplinarity is more than a new discipline or a super-discipline; it is "a different manner of seeing the world [that is] more systemic and holistic" (Max-Neef, 2005). As a last example, Nicolescu (2010) distinguishes three forms of transdisciplinary: (1) theoretical (referring to his own work and that of his collaborator, Edgar Morin), (2) phenomenological (corresponding to Gibbon's Mode 2), and (3) experimental (which is based on existing data in a diversity of fields, such as education, art, and literature).

Transdisciplinarity is often described as a promising notion, but its ability to efficiently address the world's most pressing issues still requires improvement. Although several transdisciplinary projects with non-academic stakeholders have led to significant improvements in addressing important issues, many other projects have been disappointing as the benefits claimed for participation are often not realized (Frame and Brown, 2008). One common response to overcome these limitations is to provide a better link between different types of transdisciplinarity regardless of the typology used. For example, for Scholz and Steiner (2015), a major challenge for transdisciplinarity is to better link Mode 1 and Mode 2 as a way to maintain high quality standards and to prevent transdisciplinarity from "being increasingly used for labeling any interactions between scientists and practitioners". For Max-Neef (2005), efforts are needed to perfect transdisciplinarity as a world vision "until the weak is absorbed and consolidated in the strong". Nicolescu (2010) also stresses the need to acknowledge both the diversity and the unity of his three types of transdisciplinarity (theoretical, phenomenological, experimental). In line with these different calls, some approaches have been proposed to better link different types of transdisciplinarity. For example, Rigolot (2020) suggests that quantum theory can be used as a source of insight to narrow the gap between Mode 1 and Mode 2 transdisciplinarity.

In this paper, another strategy is proposed by reframing the entire debate. Each of the mentioned typologies of transdisciplinarity has important limitations, and the very idea of a typology itself has become limited. As discussed in the next section, the notion of a
Mode 1 transdisciplinarity and the related "theoretical" transdisciplinarity in Nicolescu's terms were somewhat misleading notions from the start. In contrast, Mode 2 transdisciplinarity has evolved considerably in the last two decades, particularly with regard to its openness to shared methods and theories. The hierarchy introduced by Max-Neef (2005) between weak and strong transdisciplinarity also seems questionable. To move forward, rather than proposing another typology, it might be more fruitful to engage a dialog between transdisciplinarity as a new discipline and as a way of being. The next section presents the emergence and main characteristics of both the discipline and the way of being. Transdisciplinarity as a discipline can be seen as emerging from "Mode 2" transdisciplinarity as a result of a "bottom-up" mutualization of methodologies and theories. As an exemplary illustration, it can be related to the recent stimulating development of "integration and implementation sciences" (i2S) (Bammer, 2017; Bammer et al., 2020), although the correspondence is not exact (i2S is larger than transdisciplinarity as a discipline). Insights from complex thought (Morin, 2008) and integral theory (Wilber, 1995; Esbjörn-Hargens, 2009) are used to illustrate transdisciplinarity as a way of being. The third section of this paper presents the complementarities and creative tensions between a transdisciplinary discipline and a way of being before concluding with the added value of the proposed approach.

\section{Mode 2 transdisciplinarity and the discipline of "integration and implementation sciences"}

The emergence of a new academic discipline requires a broad research community with a common purpose that collaborates not only on a practical level but also on methodological and theoretical levels. Following this approach, transdisciplinarity as a discipline can be understood in terms of Mode 2 transdisciplinarity and insights from integration and implementation sciences. The notion of Mode 2 transdisciplinarity was adopted in the Zürich congress in 2000 by the major academic transdisciplinarity research community, which ultimately became the Swiss-based TD-net Network for Transdisciplinarity Research (McGregor, 2015a). The "Zürich approach" discarded the notion of transdisciplinary as a methodology with axioms, as proposed by Nicolescu, which was later labeled "Mode 1" (Scholz and Steiner, 2015) or "theoretical" (Nicolescu, 2010) transdisciplinarity. According to Klein (2014), the Zürich congress 2000 was a pivotal event in the evolution of transdisciplinarity discourses. Originally, Mode 2 science was characterized by six principles (Gibbons et al. 1994) that would later be used as a basis for an "idealtype" Mode 2 transdisciplinarity (Scholtz and Steiner, 2015): (1) Mode 2 knowledge is produced in the context where it will be applied; (2) it has its own distinct characteristics beyond disciplinary knowledge; (3) Mode 2 is heterogeneous in terms of skills, viewpoints and participants' experiences; (4) structures are seen as transient and evolving rather than rigidly hierarchical; (5) the resulting knowledge is socially robust and relevant for the actors involved; (6) the quality of the produced knowledge is ensured by adequate criteria and procedures (McGregor, 2015a). Following the principles of Mode 2, Scholtz and Steiner (2015) identified a possible "kernel" of transdisciplinary processes, which can be seen as a common purpose for the related community, in "the mutual learning among scientists and practitioners about a complex, societally relevant problem".

As Mode 2 transdisciplinarity emerged at the expense of the methodology proposed by Nicolescu (2010), it became characterized by the adjective "practical" by contrast. Because the Zürich approach refused to embrace an overarching methodology (i.e., Nicolescu's methodology), it became associated with "the refusal to formulate any methodology" (Nicolescu, 2010) and, correlatively, with an aversion to theoretical developments. However, recent breakthroughs have led to a move beyond what 
now appears as an over-simplification, as exemplified by the development of a new discipline of integration and implementation sciences (I2S) (Bammer, 2017). Integration and implementation sciences (i2S) does not strictly correspond to transdisciplinarity as it encompasses many other approaches, such as system dynamics, sustainability sciences and action research (Bammer, 2017). However, there is a significant overlap, as indicated in the definition of $\mathrm{i} 2 \mathrm{~S}$ as "a new discipline providing concepts and methods for conducting research on complex, realworld problems" (Bammer, 2017). In particular, the domain of application of i2S includes topics such as the synthesis of disciplinary and stakeholder knowledge, the understanding and management of diverse unknowns and the provision of integrated research support for policy and practice change (Bammer, 2017). As noted by Bammer (2017), the development of the i2S discipline was motivated by the difficulty of interdisciplinarity (including transdisciplinarity) in fitting into the mainstream and the fragmentation of methods and academic communities, which led to extensive "reinventing of methods". A major advance has been to build a methods repository, which is also open to theoretical exchanges and development (Bammer et al., 2020). In a post on the i2S b $\log ^{1}$ presenting discussions held at the $2015 \mathrm{TD}$ net conference, a group of researchers discuss the role of theory specifically for transdisciplinary research. For this group, "theory makes clear what transdisciplinary researchers value and stand for", which is why they feel "a responsibility to build and articulate it". This group also insists on the specificities of transdisciplinarity research and the importance of "holding theory lightly and approaching and using it pragmatically". While the distance from Nicolescu's overarching approach clearly remains, such recent reflections unambiguously break with the previous view of a mostly practical transdisciplinarity that is methodology and theory averse.

\section{Transdisciplinarity as a way of being}

To date, most academic debates about types of transdisciplinarity have focused on the Mode 2 or Zürich transdisciplinarity approach, on the one hand, and the theoretical work of the quantum physicist Nicolescu (2010), on the other hand (Scholtz and Steiner, 2015; Bernstein, 2015; McGregor, 2015a). Although these debates have yielded stimulating insights regarding, for example, the complementarity of Mode 2 transdisciplinarity with Nicolescu's axioms, they may have reached a limit. In particular, Nicolescu's propensity for theoretical developments and his background as a quantum physicist have contributed to the idea of a "theoretical" transdisciplinarity, as he labels it, and even further to a Mode 1 transdisciplinarity, typically associated with the image of the "ivory tower" (Scholtz and Steiner, 2015). To move the debate forward, the work of the French philosopher Edgar Morin can be used as a key reference for further exploration. Morin's work and "complex thought" are widely acknowledged as a major contribution to domains such as philosophy, sociology and biology but, surprisingly, to a lesser degree to transdisciplinarity (compared to Nicolescu). However, Morin is a cosignatory with Nicolescu of the seminal "charter of transdisciplinarity" (Nicolescu et al., 1994). Morin himself did not engage in academic debates about transdisciplinarity as Nicolescu did (which is indicative of Morin's approach to transdisciplinarity as a way of being). As summarized by Montuori (2013), "Morin's work does not come from an attempt to escape life for an ivory tower (...) but from an effort to immerse himself in it more deeply". As several other commentators have noted, Montuori (2013) shows how Morin's transdisciplinary work and well-known "complex thought" are deeply integrated with his own life experiences, including events such as the death of his mother and his participation in French resistance, about which Morin constantly reflects in journals and autobiographies. Morin is also deeply engaged in the public and political debate in France. He played a significant role, for example, in the emergence of ecological questions in the public debate (Morin and Kern, 1993). For Montuori (2013), Morin's transdisciplinary approach "does not seek to simply solve a problem, but is rather a quest for meaning derived from personal experience".

From his own life experiences (such as the lies around his mother's death when he was a child and his disillusionment with the French communist party), Edgar Morin developed a particularly strong sense of distrust towards self-deception and illusion. He became aware (and then theorized) that every form of knowledge is a construction resulting from specific sources and choices that themselves depend on historical contingencies and personal preferences (Morin, 2008). Consequently, transdisciplinarity as a way of being cannot be fairly represented by the biased perception of only one key author, including Edgar Morin. For Gidley (2016), a diversity of authors and research fields are complementary to Morin's way of thinking. For example, integral theory shows particularly stimulating complementarities (Gidley, 2016; Kelly, 2018). In line with the search for a unity of knowledge in Morin's and Nicolescu's works (Klein, 2014), integral theory is an attempt "to integrate as many approaches, theories and thinkers as possible in a common framework" (EsbjörnHargens, 2009). On the basis of the philosopher Ken Wilber's seminal work (1995), integral theory has been presented as a "theory of everything" that aims to gather "separate paradigms into an interrelated network of approaches that are mutually enriching" (Esbjörn-Hargens, 2009). Among other authors (e.g., Gidley, 2016; Kelly, 2018), Sue McGregor (2015b) has identified some strong complementarities between integral theory and transdisciplinarity, for example, with regard to the consideration of different levels of reality. For this author, integral theory can be seen as an "internal life- and world-processing orientation" (McGregor, 2015b), which precisely corresponds to the broad definition of transdisciplinarity as a way of being adopted in the present paper. A stimulating complementarity between Integral theory and Edgar Morin's complex thought lies in the integration of spiritual knowledge: whereas integral theory insists that there is some truth everywhere and gives strong credit to religions as holders of truth, Morin is open to spiritual knowledge but is also constantly skeptical (Montuori, 2013; Kelly, 2018). This skepticism is related to Morin embodied distrust towards self-deception, errors and illusions, which he sees constantly in knowledge production, including in the realm of science (Montuori, 2013; Kelly, 2018).

\section{Complementarities and creative tensions}

Some important characteristics of the i2S discipline were developed by Bammer et al. (2020) and can be used as a basis for characterizing transdisciplinarity as a discipline (although the i2S discipline is larger) in comparison with transdisciplinarity as a way of being. When transdisciplinarity is seen as a discipline (as part of i2S), it applies to particular issues or "wicked" problems (Bammer et al., 2020). More precisely, expertize in integration and implementation is required at different stages of the problem-solving process, from delimiting the problem to accommodating solutions. Bammer et al. (2020) also identify different realms where expertize can be found, which are related to communities of professional scientists or associated with academic research projects or research domains (such as unknowns and innovation). From the explorations of Bammer et al. (2020), it appears that the production of specific knowledge for the discipline of integration and implementation sciences occurs 
primarily in a community of professional scientists. On the other hand, from the perspective of a transdisciplinary way of being, every problem in real life can be framed as complex (Morin, 2008). Moreover, the relevant skills, knowledge and know-how to overcome such complex problems have been developed from ancient times and far beyond academia (Wilber, 1995). The way of being lens is also useful to make sense of why the first main practical application domain of Morin's complex thought was education (Morin, 2002; Gidley, 2016). Transdisciplinarity as a new discipline and transdisciplinarity as a way of being partly overlap. Notably, the transdisciplinary way of being provides relevant "dispositions" to engage in the transdisciplinary discipline (McGregor, 2015b). For example, participation in the public debate (agora) can be seen both as a possible characteristic of a transdisciplinary way of being (as exemplified by Edgar Morin) and as essential for the contextualization of problems in research projects (McGregor, 2015b). Reciprocally, a transdisciplinary discipline provides specific skills and a much-needed space for the expression of the transdisciplinary way of being in academia (Ross and Mitchell, 2018).

However, tensions may also occur between transdisciplinarity as a discipline and as a way of being. In particular, this distinction raises the question of the status of consciousness in transdisciplinary research projects. In line with the developmental approach of the psychologist and epistemologist Jean Piaget, who coined the term transdisciplinarity (Nicolescu, 2010), a transdisciplinary way of being is embedded in an evolutionary approach to consciousness. A typical expression of Edgar Morin is that "we are at the prehistory of the human mind", meaning that much of the human mental capacity remains to be explored. To a large extent, Morin's approach is consistent with the deep exploration of transpersonal psychology by integral scholars (Gidley, 2016; Kelly, 2018). Transpersonal psychology refers to the integration of the spiritual and transcendent aspects of the human experience with the framework of modern psychology. The transpersonal is defined as "experiences in which the sense of identity or self extends beyond the individual or personal to encompass wider aspects of humankind, life, psyche or cosmos" (Walsh and Vaughan, 1993). Correlative with this conception, in the current context of worldwide unprecedented crisis, the transdisciplinary way of being encourages consideration of ideas such as a whole civilization change (Morin, 2011) based on an evolution of human thought or consciousness (Botta, 2019). However, many transdisciplinary scholars may hesitate to consider these ideas in the solution space of research projects. In particular, the potential tension is apparent in relation to integral theory, which explicitly and significantly includes spiritual knowledge and often associates an evolution of consciousness with processes of "awakening" (Wilber, 1995). Although integral theory is currently used by a large number of transdisciplinary scholars (Esbjörn-Hargens, 2009), it may be considered by other transdisciplinary scholars to be non-scientific and misleading. This tension is mostly implicit and seldom discussed in the literature, but it can manifest concretely as part of transdisciplinary research projects. Tension can particularly occur between a search for consensus that integrates and respects diverse stakeholders' viewpoints as they are and the aim of transforming ways of thinking (including those of scientists themselves). In the first case, transdisciplinarity (as a discipline) is a means by which scientists contribute to problem solving. In the second case, transdisciplinarity (as a way of being) is also a solution that must be enhanced in society at large.

\section{Conclusion}

Transdisciplinarity is a promising notion, but its ability to efficiently address the world's most pressing issues has been intensively debated. To date, most debates have been structured by identifying several types of transdisciplinarity, generally with a theoretical versus practical dichotomy, and their possible linkages. In the last two decades, important efforts to mutualize methodologies and theories have led to the emergence of a discipline of integration and implementation, which enables the conception of transdisciplinarity as a discipline. Somewhat paradoxically, such a discipline seems to emerge from "Mode 2" transdisciplinarity as a result of a "bottomup" mutualization rather than from the so-called Mode 1 "innerscience" transdisciplinarity. This distinction shows the interpenetration of Mode 2 and Mode 1 transdisciplinarity and the limits of existing typologies of transdisciplinarity. On the other hand, when transdisciplinarity is taken as a way of being, the need for knowledge and know-how for integration and implementation extends far beyond the scope of research projects and appears constantly and ubiquitously in real life. The relevant resources can be found not only in academia but also in domains such as literature and religion, keeping in mind the constant risks of errors and illusion (including in science itself). Compared to existing typologies, the consideration of transdisciplinarity as a discipline and a way of being could generate new insights in the ongoing debate about the potential and effectiveness of transdisciplinary approaches. Complementarities can be considered in terms of personal dispositions for the discipline and of a space for expression for the way of being in academia. The proposed reframing also sheds light on the status of consciousness in transdisciplinary research projects. In a sense, consciousness can be seen as a critical "unknown" for the activity of integration and implementation and a major topic for further investigation.

Received: 7 May 2020; Accepted: 4 September 2020;

Published online: 22 September 2020

\section{Note}

1 "What is the role of theory in transdisciplinary research?", by the Workshop Group on Theory at 2015 Basel International Transdisciplinary Conference: https://i2insights. org/2016/02/17/role-of-theory-in-transdisciplinary-research/

\section{References}

Bammer G (2017) Should we discipline interdisciplinarity? Pal Commun 3(1):1-4 Bammer G, O'Rourke M, O'Connell D et al. (2020) Expertise in research integration and implementation for tackling complex problems: when is it needed, where can it be found and how can it be strengthened? Pal Commun 6 (1):1-16

Bernstein JH (2015) Transdisciplinarity: a review of its origins, development, and current issues. J Res Practice 11(1):R1

Botta M (2019) A macrohistory perspective on neo-collectivism as a higher evolutionary stage of consciousness embedded in the Holarchic evolutionary model. Futures 113:102419

Esbjörn-Hargens S (2009) A overview of integral theory. An All-Inclusive Framework for the 21st Century. Integral Institute, Resource Paper 1:1-24

Frame B, Brown J (2008) Developing post-normal technologies for sustainability. Ecol Econ 65:225-241. https://doi.org/10.1016/j.ecolecon.2007.11.010

Gibbons M, Limoges C, Nowotny H et al. (1994) The new production of knowledge. Sage, London, England

Gidley JM (2016) Postformal education: a philosophy for complex futures (Vol. 3). Springer

Kelly SM (2018) Transpersonal psychology and the paradigm of complexity. J Conscious Evol 1(1):8

Klein JT (2014) Discourse of transdisciplinarity: looking back to the future. Futures 63:68-74

Lang DJ, Wiek A, Bergmann M et al. (2012) Transdisciplinary research in sustainability science: practice, principles, and challenges. Sustain Sci 7 (1):25-43

Max-Neef MA (2005) Foundations of transdisciplinarity. Ecol Econ 53(1):5-16

McGregor SL (2015a) The Nicolescuian and Zürich approaches to transdisciplinarity. Integral Leader Rev 15(2):6-16

McGregor SL (2015b) Integral dispositions and transdisciplinary knowledge creation. Integral Leader Rev 15(1):1-15

Montuori A (2013) Complex thought: an overview of Edgar Morin's intellectual journey. MetaIntegral Foundation, Resource Paper, June 2013

Morin E (2002) Seven complex lessons in education for the future. Unesco, Paris Morin E (2008) La Méthode. Le Seuil, Paris 
Morin E (2011) La Voie: Pour l'avenir de l'humanité. Fayard, Paris

Morin E, Kern B (1993) Terre-patrie. Editions du Seuil, Paris

Nicolescu B (2010) Methodology of transdisciplinarity: Levels of reality, logic of the included middle and complexity. Transdiscipl J Eng Sci 1:17-32

Nicolescu B, Morin E, de Freitas L (1994) The charter of transdisciplinarity. Manifesto of transdisciplinarity

Rigolot C (2020) Quantum theory as a source of insights to close the gap between Mode 1 and Mode 2 transdisciplinarity: potentialities, pitfalls and a possible way forward. Sustain Sci 15(2):663-669

Ross K, Mitchell C (2018) Transforming transdisciplinarity: an expansion of strong transdisciplinarity and its centrality in enabling effective collaboration. In: Fam D, Neuhauser L, Gibbs P (eds) Transdisciplinary theory, practice and education: the art of collaborative research and collective learning. Springer International Publishing

Scholz RW, Steiner G (2015) The real type and ideal type of transdisciplinary processes: part II-what constraints and obstacles do we meet in practice? Sustain Sci 10(4):653-671

Walsh RE, Vaughan FE (1993) Paths beyond ego: the transpersonal vision. Perigee Books

Wilber K (1995) Sex, ecology, spirituality: the spirit of evolution. Shambhala Publications

\section{Acknowledgements}

This paper was funded by the French government IDEX-ISITE initiative 16-IDEX-0001 (CAP 20-25). This paper has benefited from discussions with Isabelle Arpin, Cécile

Barnaud, Gaël Plumecocq, and INRAE ACT division (Sciences for Action and Transitions).

\section{Competing interests}

The author declares no competing interests.

\section{Additional information}

Correspondence and requests for materials should be addressed to C.R.

Reprints and permission information is available at http://www.nature.com/reprints

Publisher's note Springer Nature remains neutral with regard to jurisdictional claims in published maps and institutional affiliations.

(c) (i) Open Access This article is licensed under a Creative Commons Attribution 4.0 International License, which permits use, sharing, adaptation, distribution and reproduction in any medium or format, as long as you give appropriate credit to the original author(s) and the source, provide a link to the Creative Commons license, and indicate if changes were made. The images or other third party material in this article are included in the article's Creative Commons license, unless indicated otherwise in a credit line to the material. If material is not included in the article's Creative Commons license and your intended use is not permitted by statutory regulation or exceeds the permitted use, you will need to obtain permission directly from the copyright holder. To view a copy of this license, visit http://creativecommons.org/ licenses/by/4.0/.

(C) The Author(s) 2020 